Article

\title{
Synthesis of Tosyl- and Nosyl-Ended Polyisobutylenes with High Extent of Functionalities: The Effect of Reaction Conditions
}

\author{
Balázs Pásztói ${ }^{1,2, * \mathbb{0}}$, Tobias M. Trötschler ${ }^{3,4,5}$, Ákos Szabó ${ }^{1}$, Györgyi Szarka ${ }^{1}$, \\ Benjamin Kerscher ${ }^{3,4} \mathbb{D}^{-}$, Rolf Mülhaupt ${ }^{3,4,5, *}$ and Béla Iván ${ }^{1, *(\mathbb{D}}$ \\ 1 Polymer Chemistry Research Group, Institute of Materials and Environment Chemistry, \\ Research Centre for Natural Sciences, Magyar tudósok körútja 2, H-1117 Budapest, Hungary; \\ szabo.akos@ttk.hu (Á.S.); szarka.gyorgyi@ttk.hu (G.S.) \\ 2 George Hevesy PhD School of Chemistry, Institute of Chemistry, Faculty of Science, \\ Eötvös Loránd University, Pázmány Péter sétány 2, H-1117 Budapest, Hungary \\ 3 Institute for Macromolecular Chemistry, University of Freiburg, Stefan-Meier-Str. 31, D-79104 Freiburg, \\ Germany; ttroet@yahoo.de (T.M.T.); benjamin_kerscher@web.de (B.K.) \\ 4 Freiburg Materials Research Center, University of Freiburg, Stefan-Meier-Str. 21, D-79104 Freiburg, Germany \\ 5 Freiburg Center for Interactive Materials and Bioinspired Technologies (FIT), University of Freiburg, \\ Georges-Köhler-Allee 105, D-79110 Freiburg, Germany \\ * Correspondence: pasztoi.balazs@ttk.hu (B.P.); rolf.muelhaupt@makro.uni-freiburg.de (R.M.); \\ ivan.bela@ttk.hu (B.I.)
}

Received: 7 October 2020; Accepted: 24 October 2020; Published: 28 October 2020

check for updates

\begin{abstract}
Endfunctional polymers possess significant industrial and scientific importance. Sulfonyl endgroups, such as tosyl and nosyl endfunctionalities, due their ease of substitution are highly desired for a variety of polymer structures. The sulfonylation of hydroxyl-terminated polyisobutylene (PIB-OH), a chemically and thermally stable, biocompatible, fully saturated polymer, with tosyl chloride $(\mathrm{TsCl})$ and nosyl chloride $(\mathrm{NsCl})$ is presented in this study. PIB-OHs derived from commercial exo-olefin-ended PIB ( $\left.\mathrm{PIB}_{\text {exo }}-\mathrm{OH}\right)$ and allyl-terminated polymer made via quasiliving carbocationic polymerization of isobutylene $\left(\mathrm{PIB}_{\text {all }}-\mathrm{OH}\right)$ were tosylated and nosylated in the presence of 4-dimethylaminopyridine (DMAP), pyridine and 1-methylimidazole (1-MI) catalysts and triethylamine (TEA). Our systematic investigations revealed that the end product distribution strongly depends on the relative amount of the components, especially that of TEA. While PIB exo-OTs with quantitative endfunctionality is readily formed from $\mathrm{PIB}_{\mathrm{exo}}-\mathrm{OH}$, its nosylation is not as straightforward. During sulfonylation of $\mathrm{PIB}_{\text {all }}-\mathrm{OH}$, the formed tosyl and nosyl endgroups are easily substituted with chloride ions, formed in the first step of sulfonylation, leading to chloride termini. We found that decreased amounts of TEA afford the synthesis of $\mathrm{PIB}_{\text {all }}-\mathrm{OTs}$ and $\mathrm{PIB}_{\mathrm{all}}-\mathrm{ONs}$ with higher than $90 \%$ endfunctionalities. These sulfonyl-ended PIBs open new ways for utilizing PIB in various fields and in the synthesis of novel PIB-containing macromolecular architectures.
\end{abstract}

Keywords: isobutylene; tosyl-ended polyisobutylene; nosyl-ended polyisobutylene; quasiliving carbocationic polymerization (QLCCP); allyl-terminated polyisobutylene; exo-olefin ended polyisobutylene; hydroxyl-ended polyisobutylene; 4-dimethylaminopyridine (DMAP); trimethylamine (TEA)

\section{Introduction}

Functional polymers with terminal and or pendant functionalities have significant industrial and scientific importance, and as a consequence, intensive research and developments have been taking place with such polymers worldwide. Among these macromolecular materials, functional polyisobutylenes 
(PIBs) have gained remarkable interest in the last couple of years (see e.g., Refs. 1-30 and references therein). This is mainly due to the demands to increase the average endfunctionality by either conventional or quasiliving carbocationic polymerizations, or to the utilization of functional PIBs as building blocks in a variety of new materials with advanced application possibilities. PIB has a fully saturated, chemically inert backbone with low glass transition temperature, high thermal and oxidative stability, outstanding barrier properties, etc. Based on these attractive features, functional PIBs and its copolymers have already gained broad fields of applications, e.g., starting material of butyl rubbers, oil, fuel and lubricant additives, sealants, adhesives, insulating materials, and the component of biomedical devices on the basis of its biocompatibility.

In spite of the availability of PIBs with a wide range of endfunctionalities [1-36], a reliable process for certain highly desired endfunctional PIBs with high extents of reactive chain end functionalities, for instance, organosulfonates, such as tosyl- or nosyl-ended PIBs, are still lacking. The most convenient way to obtain PIB-sulfonates is the sulfonylation of hydroxyl-terminated PIBs (PIB-OHs) by the corresponding sulfonyl chlorides, e.g., tosyl chloride $(\mathrm{Ts} C l)$ or nosyl chloride $(\mathrm{NsCl})$ as shown in Scheme 1. PIB-OHs are usually prepared by hydroboration/oxidation of olefin-terminated PIBs [31,32]. While commercial PIBs with relatively broad molecular weight distributions (MWD) have about $80 \%$ reactive exo-olefin functionality [1,4-6,8,9] (PIB-Exo), the inifer method [33] and quasiliving carbocationic polymerization (QLCCP) results in PIB-Exo with quantitative vinylidene endgroups [34,35]. In situ allylation by endquenching of QLCCP of isobutylene with allyltrimethylsilane yields PIBs directly with allyl termini (PIB-All) [32]. It has to be noted that significant efforts have been made to increase the exo-olefin functionality in PIB-Exo by conventional carbocationic polymerization in recent years [1,4-6,9,24-29]. Both PIB-Exo and PIB-All were converted to PIB-OHs [31,32,36], which in principle can be converted to PIB-sulfonates, e.g., tosylates, nosylates and mesylates. The interest in such PIBs is based on the fact that alkyl tosylates are among the most versatile compounds for substitution reactions because the tosyl group is an excellent leaving group. As widely accepted, tosylates can be prepared by the reaction of tosyl chloride and an alcohol. Typically, bases promote this process by capturing the generated $\mathrm{HCl}$ during the reaction. Catalysts, such as 4-dialkylaminopyridines, like 4-dimethylaminopyridine (DMAP) and tertiary amines, e.g., triethylamine (TEA), proved to be effective for a wide range of species [37-39]. Furthermore, imidazole-based sulfonylation was also described $[40,41]$. Although these catalysts are efficient in tosylation of alcohols of low molecular weights in most cases, undesired side reactions were observed for some species and under certain reaction conditions. Mostly, the formed tosyl group is substituted by the chloride anion yielding chloride functional group $[39,42]$. While tosylates are preferred in organic reactions and have a quite extensive literature background, nosylates, despite their even better synthetic features in substitution reactions [43-45], have not been explored intensively so far. Based on these characteristics of tosylates and nosylates, effective tosylation/nosylation of PIB-OHs is expected to lead to PIBs with tosyl and nosyl endfunctionalities. These can be utilized in a wide range of subsequent substitution reactions and thus in the preparation of a variety of new macromolecular materials. It has to be mentioned that tosylates and nosylates can also be applied as macroinitiators, e.g., for quasiliving ring-opening polymerization of oxazolines [46]. Consequently, PIBs with tosyl or nosyl chain ends would provide unique opportunities to prepare an array of novel macromolecular materials.

Based on the current literature, very limited knowledge exists on PIBs with sulfonate (tosylate, nosylate, mesylate) endgroups. In an early attempt, linear and three-arm star PIB-OHs were tosylated with excess $\mathrm{TsCl}$ in the presence of DMAP and TEA as bases in dichloromethane (DCM) [47]. Although complete consumption of the hydroxyl groups was claimed, detailed analysis of the products was not carried out. However, it was found that using these tosylated PIBs as macroinitiators for the quasiliving cationic ring-opening polymerization (CROP) of 2-methyl-2-oxazoline resulted only in $70-80 \%$ blocking efficiency, indicating incomplete initiation of the CROP process by the chain ends, which might be an indication of incomplete tosylation. As found by us recently [48] and during our preliminary experiments, lower than quantitative endfunctionalization was achieved by 
reacting $\mathrm{TsCl}$ with PIB-OH under similar conditions as reported [47]. Converting the hydroxyl group of PIB-OH prepared from industrial PIB-Exo by methanesulfonyl chloride (mesyl chloride, $\mathrm{MsCl}$ ) led to mesylated PIB, which was used as an intermediate for polyisobutylene supported catalyst systems $[49,50]$. However, detailed analysis of this process and the resulting polymers or the average endfunctionality has not been reported in the case of these sulfonylations.

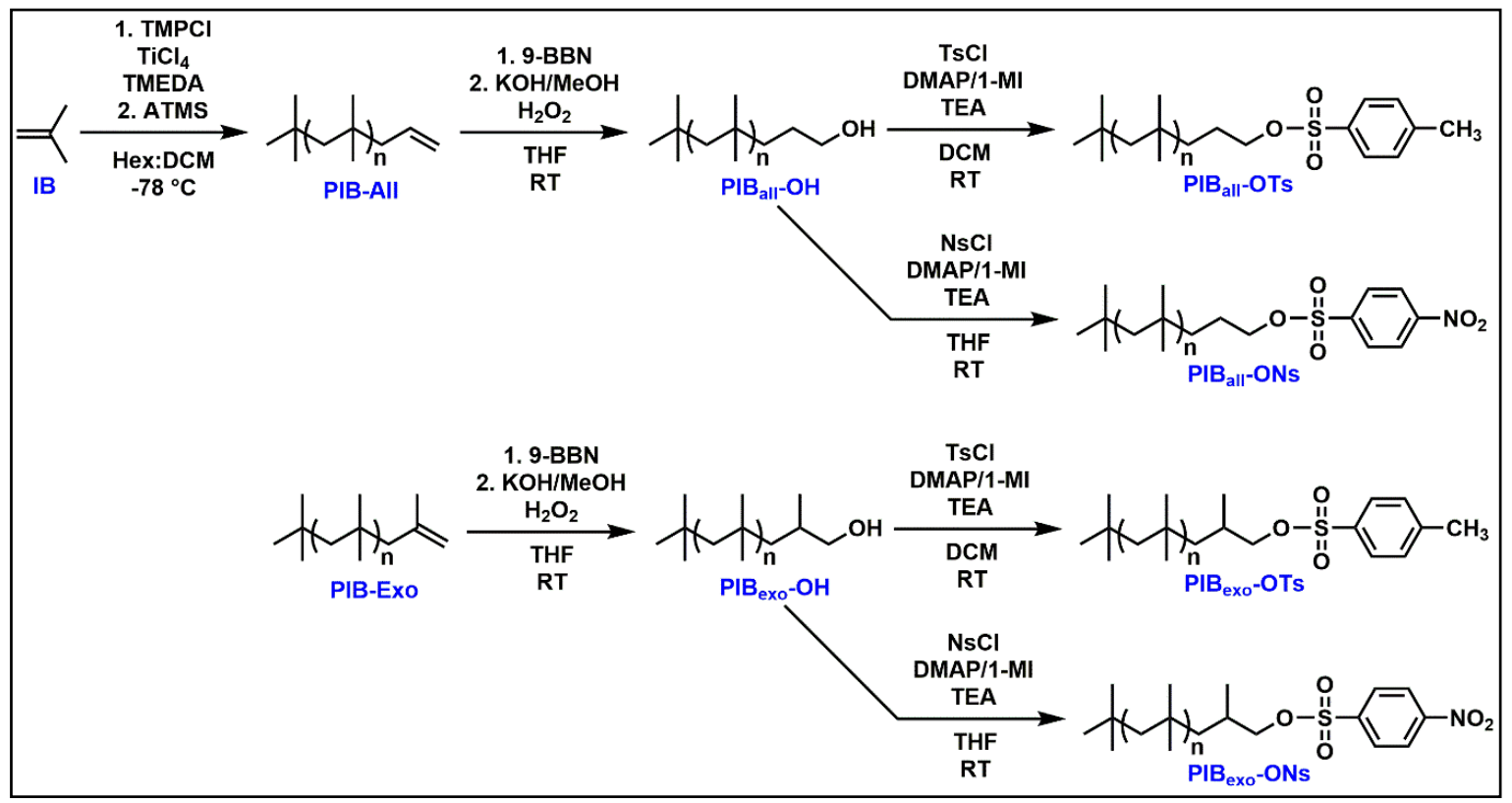

Scheme 1. The synthesis routes for the preparation of tosyl- and nosyl-ended polyisobutylenes derived from exo-olefin-ended (PIB-Exo) and allyl-terminated (PIB-All) polymers (PIB-All was obtained by quasiliving carbocationic polymerization).

Herein, we report on our systematic investigations aiming at to determine the effect of reaction conditions on the efficiency of tosylation and nosylation of PIB-OHs derived from commercially available PIB-Exo and laboratory PIB-All prepared by QLCCP. Our definite goal was to reveal the reaction parameters which result in high tosylation and nosylation yields, i.e., high tosyl and nosyl endfunctionalities. Thorough experiments were also carried out on the influence of the origin of the PIB-OH, i.e., $\mathrm{PIB}_{\text {exo }}-\mathrm{OH}$ or $\mathrm{PIB}_{\text {all }}-\mathrm{OH}$, the ratio of the reagents and the reaction times on the endfunctionalities of the sulfonylated PIBs.

\section{Materials and Methods}

\subsection{Materials}

Dichloromethane (DCM, 99.9\%, Molar Chemicals, Halásztelek, Hungary), tetrahydrofuran (THF, 99.9\%, VWR Chemicals, West Chester, PA, USA), benzotrifluoride (BTF, $\geq 99 \%$, Sigma-Aldrich, St. Louis, $\mathrm{MO}, \mathrm{USA}$ ) and 2-ethyl-2-oxazoline (EtOx, 99+\%, Aldrich, St. Louis, MO, USA) were refluxed on $\mathrm{CaH}_{2}$ for a couple of hours and distilled over it under $\mathrm{N}_{2}$ atmosphere freshly before use. Triethylamine (TEA, $\geq 99.0 \%$, TCI Chemicals, Tokyo, Japan) and 1-methylimidazole (1-MI, $\geq 99 \%$, Sigma-Aldrich, St. Louis, MO, USA) was distilled under $\mathrm{N}_{2}$ atmosphere freshly before use. Glissopal 1000 (BASF SE, Ludwigshafen, Germany), p-toluenesulfonyl chloride (tosyl chloride, $\mathrm{TsCl}, \geq 99.0 \%$, TCI Chemicals, Tokyo, Japan), p-nitrobenzenesulfonyl chloride (nosyl chloride, $\mathrm{NsCl}, 97 \%$, Sigma-Aldrich, St. Louis, MO, USA) and 4-dimethylaminopyridine (DMAP, $\geq 99.9 \%$, Sigma-Aldrich, St. Louis, MO, USA) were used as receive. 


\subsection{Characterization}

NMR spectroscopy. ${ }^{1} \mathrm{H}$ NMR spectra of all endfunctional PIBs were recorded on a Varian $500 \mathrm{MHz}$ spectrometer. All measurements were performed in $\mathrm{CDCl}_{3}$ as solvent and at $30{ }^{\circ} \mathrm{C}$. For spectra calibration of the ${ }^{1} \mathrm{H}$ NMR spectra, the chloroform peak was set to $7.26 \mathrm{ppm}$.

Gelpermeation chromatography (GPC). The GPC equipment was composed of a Waters 515 HPLC pump, Waters Styragel column set with three columns (HR1, HR2, HR4), and it was equipped with an Aligent 390 RI detector. THF was used as mobile phase with a flow rate of $1 \mathrm{~mL} / \mathrm{min}$. The average molar masses and the polydispersity $\left(\mathrm{M}_{\mathrm{w}} / \mathrm{M}_{n}\right)$, were determined by the use of a calibration made with narrow MWD polystyrene standards in the molecular weight range of 104 to $6 \times 10^{5} \mathrm{Da}$.

\subsection{Synthesis of PIB-All}

A solution of 2-chloro-2,4,4-trimethylpentane (TMPCl, $4.1 \mathrm{~g}, 0.03 \mathrm{~mol})$ in n-hexane $(1520 \mathrm{~mL})$ and $\operatorname{DCM}(1240 \mathrm{~mL})$ was cooled down in a dry ice-isopropanol mixture to $-78{ }^{\circ} \mathrm{C}$. To this reaction solution, under continuous stirring, tetramethylethylenediamine (TMEDA, $4.1 \mathrm{~mL}, 3.2 \mathrm{~g}$, $0.03 \mathrm{~mol}, 1.0 \mathrm{eq}$.) was given. Afterward, $\mathrm{TiCl}_{4}(18.2 \mathrm{~mL}, 31.4 \mathrm{~g}, 0.17 \mathrm{~mol}, 6.0$ eq.) and isobutylene (IB, $32.6 \mathrm{~mL}, 23.5 \mathrm{~g}, 0.42 \mathrm{~mol}$, 15.2 eq.) were carefully added and the mixture was stirred at $-78{ }^{\circ} \mathrm{C}$ for $30 \mathrm{~min}$. After complete conversion of IB, pre-chilled allyltrimethylsilane (ATMS, $8.8 \mathrm{~mL}, 8.3 \mathrm{~g}, 0.06 \mathrm{~mol}, 2$ eq.) was given and the solution was stirred for $30 \mathrm{~min}$. Finally, the reaction was stopped with the addition of cold $\mathrm{MeOH}$ $(200 \mathrm{~mL})$. The mixture was warmed up to room temperature, which resulted a two-phase mixture (including a higher phase of $n$-hexane and a lower phase of $\mathrm{DCM} / \mathrm{MeOH}$ ). The $\mathrm{n}$-hexane phase was separated and washed with a solution of $\mathrm{NaHCO}_{3}$ in $\mathrm{H}_{2} \mathrm{O}(250 \mathrm{~mL})$ three times, dried over $\mathrm{MgSO}_{4}$ overnight and cleaned up via filtering. The solvent was removed under reduced pressure and the product was dried under vacuum at $60^{\circ} \mathrm{C}$ until constant weight. PIB-All was obtained as a colourless, clean, viscous liquid (yield: $22.4 \mathrm{~g}, 81 \%) .{ }^{1} \mathrm{H}$ NMR $\left(500 \mathrm{MHz}, \mathrm{CDCl}_{3}, 30^{\circ} \mathrm{C}\right): \delta=0.76-1.80(\mathrm{~m}, 116 \mathrm{H})$, $1.95-2.07(\mathrm{~d}, 2 \mathrm{H}), 4.92-5.07(\mathrm{~m}, 2 \mathrm{H}), 5.77-5.93(\mathrm{~m}, 1 \mathrm{H})$ ppm. GPC: $\left.\mathrm{M}_{\mathrm{n}}=820 \mathrm{~g} / \mathrm{mol}, \mathrm{D}=1.16\right)$.

\subsection{Synthesis of $\mathrm{PIB}_{\text {all }}-\mathrm{OH}$}

PIB-All (7.0 g, $7.78 \mathrm{mmol})$ was dissolved in dry THF $(35 \mathrm{~mL})$ under nitrogen atmosphere. Afterwards, 0.5 M solution of 9-borabicyclo[3.3.1]nonane in THF (9-BBN, 0.5 M, $78 \mathrm{~mL}, 0.039 \mathrm{~mol}$, 5 eq.) was added dropwise and the mixture was stirred for $5 \mathrm{~h}$ at room temperature. Into this mixture, $\mathrm{KOH}(6.5 \mathrm{~g}, 0.12 \mathrm{~mol}, 15 \mathrm{eq}$.) in $\mathrm{MeOH}$ solution $(43 \mathrm{~mL})$ was carefully added, then the reaction mixture was cooled down with an ice bath, and aqueous $\mathrm{H}_{2} \mathrm{O}_{2}(30 \%, 13.2 \mathrm{~mL}, 4.0 \mathrm{~g}, 0.12 \mathrm{~mol}, 15 \mathrm{eq}$.) was dropped under constant stirring. The reaction mixture was stirred overnight at room temperature. After this, n-hexane $(70 \mathrm{~mL})$ and $\mathrm{H}_{2} \mathrm{O}(20 \mathrm{~mL})$ were added, and the organic phase of the two-phase mixture was separated, washed with a solution of $\mathrm{NaHCO}_{3}$ in $\mathrm{H}_{2} \mathrm{O}(20 \mathrm{~mL})$ three times, dried over $\mathrm{MgSO}_{4}$ overnight and cleaned up via filtering. The solvent was removed under reduced pressure and the product was dried under vacuum at $60^{\circ} \mathrm{C}$ until constant weight. $\mathrm{PIB}_{\text {all }}-\mathrm{OH}$ was obtained as a colourless, clean, viscous liquid (yield: $6.9 \mathrm{~g}, 99 \%) .{ }^{1} \mathrm{H}$ NMR $\left(500 \mathrm{MHz}, \mathrm{CDCl}_{3}, 30{ }^{\circ} \mathrm{C}\right): \delta=0.78-1.91$ $(\mathrm{m}, 130 \mathrm{H}), 3.55-3.68(\mathrm{t}, 2 \mathrm{H})$. GPC: $\mathrm{M}_{\mathrm{n}}=1160 \mathrm{~g} / \mathrm{mol}, \mathrm{D}=1.18$.

\subsection{Synthesis of $\mathrm{PIB}_{\text {exo }}-\mathrm{OH}$}

PIB-Exo (50.0 g, $50.0 \mathrm{mmol})$ was dissolved in dry THF $(250 \mathrm{~mL})$ under nitrogen atmosphere. Afterward, 0.5 M solution of 9-borabicyclo[3.3.1]nonane in THF (9-BBN, 0.5 M, $500 \mathrm{~mL}, 0.250 \mathrm{~mol}$, 5 eq.) was added dropwise and the mixture was stirred for $4 \mathrm{~h}$ at room temperature. Into this mixture, $\mathrm{KOH}(70.1 \mathrm{~g}, 1.25 \mathrm{~mol}, 25 \mathrm{eq}$.$) in \mathrm{MeOH}$ solution $(440 \mathrm{~mL})$ was carefully added, then the reaction mixture was cooled down with an ice bath, and aqueous $\mathrm{H}_{2} \mathrm{O}_{2}(30 \%, 29.3 \mathrm{~mL}, 42.5 \mathrm{~g}, 1.25$ mol, 25 eq.) was dropped under constant stirring. The reaction mixture was stirred overnight at room temperature. After this, n-hexane $(250 \mathrm{~mL})$ and $\mathrm{H}_{2} \mathrm{O}(100 \mathrm{~mL})$ were added, and the organic phase of the two-phase mixture was separated, washed with a solution of $\mathrm{NaHCO}_{3}$ in $\mathrm{H}_{2} \mathrm{O}(100 \mathrm{~mL})$ three times, dried over 
$\mathrm{MgSO}_{4}$ overnight and cleaned up via filtering. The solvent was removed under reduced pressure and the product was dried under vacuum at $60^{\circ} \mathrm{C}$ until constant weight. The final product was resulted after precipitation from THF to tenfold excess of $\mathrm{MeOH}$. $\mathrm{PIB}_{\text {exo }}-\mathrm{OH}$ was obtained as a colorless, clean, viscous liquid (yield: $43.6 \mathrm{~g}, 86 \%) .{ }^{1} \mathrm{H}$ NMR $\left(500 \mathrm{MHz}, \mathrm{CDCl}_{3}, 30^{\circ} \mathrm{C}\right): \delta=0.88-1.80(\mathrm{~m}, 216 \mathrm{H}), 3.26-3.53$ $(\mathrm{m}, 2 \mathrm{H}), 4.77-4.86$ ( ${ }^{*}$ coupled, $\left.\mathrm{m}, 1 \mathrm{H}\right), 5.09-5.19$ (*endo, $\left.\mathrm{m}, 1 \mathrm{H}\right) . \mathrm{GPC}: \mathrm{M}_{\mathrm{n}}=1360 \mathrm{~g} / \mathrm{mol}, \mathrm{D}=1.53$.

\subsection{Experiments on the Tosylation of $P I B_{\text {exo }}-\mathrm{OH}$ and $\mathrm{PIB}_{\text {all }}-\mathrm{OH}$}

$0.1 \mathrm{~g}$ or $0.2 \mathrm{~g}$ of PIB-OH was dissolved in dry DCM and the solution was added to a previously heat-dried small glass vial equipped with a magnetic stirrer. The vial was carefully closed with a septum cap and nitrogen was transferred through solution for several minutes. Afterwards, calculated amount of TEA and the catalyst (DMAP or 1-methylimidazole in DCM solution) were added with constant stirring. Finally, tosyl chloride in DCM solution was given dropwise to the reaction mixture. Reaction was conducted at room temperature; samples were withdrawn at defined times and precipitated into large excess of $\mathrm{MeOH}$. Polymer was isolated, washed with $\mathrm{MeOH}$ and dried under vacuum at $40{ }^{\circ} \mathrm{C}$ until constant weight. Dry product was analyzed by ${ }^{1} \mathrm{H}$ NMR spectroscopy to determine the conversion of hydroxyl endgroup.

\subsection{Experiments on the Nosylation of $\mathrm{PIB}_{\text {exo }}-\mathrm{OH}$ and $\mathrm{PIB}_{\text {all }}-\mathrm{OH}$}

$0.1 \mathrm{~g}$ or $0.2 \mathrm{~g}$ of PIB-OH was dissolved in dry THF and the solution was added to a previously heat-dried small glass vial equipped with a magnetic stirrer. The vial was carefully closed with a septum cap, and nitrogen was transferred through solution for several minutes. Afterward, calculated amount of TEA and the catalyst (DMAP or 1-methylimidazole in THF solution) were added with constant stirring. Finally, nosyl chloride in THF solution was given dropwise to the reaction mixture. Reaction was conducted at room temperature; samples were withdrawn at defined times and precipitated into large excess of $\mathrm{MeOH}$. Polymer was isolated, washed with $\mathrm{MeOH}$ and dried under vacuum at $40^{\circ} \mathrm{C}$ until constant weight. The dry product was analyzed by ${ }^{1} \mathrm{H}$ NMR spectroscopy to determine the conversion of the hydroxyl endgroup.

\subsection{Synthesis of $\mathrm{PIB}_{\text {all }}-\mathrm{OTs}$}

$\mathrm{PIB}_{\mathrm{all}}-\mathrm{OH}(37.0 \mathrm{~g}, 30.8 \mathrm{mmol})$ was dissolved in dry DCM $(370 \mathrm{~mL})$ under nitrogen atmosphere. Afterwards, TEA ( $21.5 \mathrm{~mL}, 15.6 \mathrm{~g}, 0.15 \mathrm{~mol}, 5 \mathrm{eq}$.) and 1-methylimidazole $(4.9 \mathrm{~mL}, 5.1 \mathrm{~g}, 62 \mathrm{mmol}$, 2 eq.) were added under continuous stirring. After complete dissolution of the reagents, tosyl chloride (58.8 g, $0.31 \mathrm{~mol}, 10 \mathrm{eq}$.) in DCM solution was dropped into the reaction mixture carefully while cooled down with an ice-bath. The reaction content was warmed up to room temperature and stirred overnight. After the addition of $\mathrm{MeOH}(50 \mathrm{~mL})$, the mixture was stirred for $30 \mathrm{~min}$, concentrated and precipitated into tenfold excess of $\mathrm{MeOH}(2000 \mathrm{~mL})$. Raw product was isolated, washed with $\mathrm{MeOH}$ $(100 \mathrm{~mL})$ several times, dried under vacuum at $60{ }^{\circ} \mathrm{C}$. Then it was resolved in $\mathrm{n}$-hexane $(150 \mathrm{~mL})$, filtered if necessary, precipitated again into tenfold excess of $\mathrm{MeOH}(1500 \mathrm{~mL})$, the product was isolated, washed with $\mathrm{MeOH}(100 \mathrm{~mL})$ several times and dried under vacuum at $60^{\circ} \mathrm{C}$ until constant weight. Precipitation procedure was usually conducted three times, but until the dry product was completely clear and lost the initial yellowish colour. $\mathrm{PIB}_{\text {all }}$-OTs was obtained as a colourless, clean, viscous liquid (yield: $36.7 \mathrm{~g}, 88 \%) .{ }^{1} \mathrm{H}$ NMR $\left(500 \mathrm{MHz}, \mathrm{CDCl}_{3}, 30{ }^{\circ} \mathrm{C}\right): \delta=0.65-1.68(\mathrm{~m}, 192 \mathrm{H}), 2.39-2.50(\mathrm{~s}, 3 \mathrm{H})$, 3.92-4.07 (t, 2H), 7.31-7.38 (d, 2H), 7.73-7.87 (d, 2H) ppm. GPC: $\mathrm{M}_{\mathrm{n}}=1480 \mathrm{~g} / \mathrm{mol}, \mathrm{D}=1.16$.

\subsection{Synthesis of $P I B_{\text {all }}-O N s$}

$\mathrm{PIB}_{\text {all }}-\mathrm{OH}(3.45 \mathrm{~g}, 3.45 \mathrm{mmol})$ was dissolved in dry THF $(50 \mathrm{~mL})$ under nitrogen atmosphere. Afterwards, TEA $(2.4 \mathrm{~mL}, 1.7 \mathrm{~g}, 0.017 \mathrm{~mol}, 5$ eq. $)$ and 1-methylimidazole $(0.55 \mathrm{~mL}, 0.67 \mathrm{~g}, 6.9 \mathrm{mmol}$, 2 eq.) were added under continuous stirring. After complete dissolution of the reagents, nosyl chloride (7.65 g, $0.035 \mathrm{~mol}, 10 \mathrm{eq}$.$) in THF solution was dropped into the reaction mixture carefully while$ cooled down with an ice-bath. The reaction content was warmed up to room temperature and stirred 
overnight. After the addition of $\mathrm{MeOH}(10 \mathrm{~mL})$, the mixture was stirred for $30 \mathrm{~min}$, concentrated and precipitated into tenfold excess of $\mathrm{MeOH}(500 \mathrm{~mL})$. Raw product was isolated, washed with $\mathrm{MeOH}(20 \mathrm{~mL})$ several times, dried under vacuum at $60^{\circ} \mathrm{C}$. Then it was resolved in n-hexane $(35 \mathrm{~mL})$, filtered if necessary, precipitated again into tenfold excess of $\mathrm{MeOH}(350 \mathrm{~mL})$, the product was isolated, washed with $\mathrm{MeOH}(20 \mathrm{~mL})$ several times and dried under vacuum at $60^{\circ} \mathrm{C}$ until constant weight. The precipitation procedure was usually conducted three times until the dry product was completely

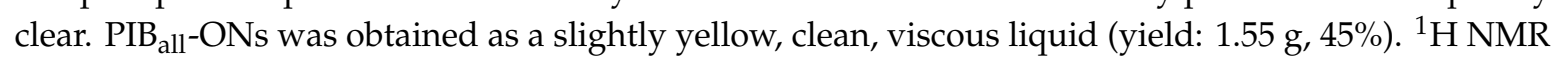
$\left(500 \mathrm{MHz}, \mathrm{CDCl}_{3}, 30{ }^{\circ} \mathrm{C}\right): \delta=0.78-1.86(\mathrm{~m}, 147 \mathrm{H}), 3.46-3.53$ ( $\left.{ }^{*} \mathrm{PIB}-\mathrm{Cl}, \mathrm{t}, 2 \mathrm{H}\right), 4.07-4.16(\mathrm{t}, 2 \mathrm{H}), 8.07-8.18$ $(\mathrm{d}, 2 \mathrm{H}), 8.36-8.45(\mathrm{~d}, 2 \mathrm{H}) \mathrm{ppm}$. GPC: $\mathrm{M}_{\mathrm{n}}=1310 \mathrm{~g} / \mathrm{mol}, \mathrm{D}=1.11$.

\section{Results and Discussion}

In order to study the effect of the chain end structure on tosylation and nosylation, both exo-olefinand allyl-ended PIBs were used as starting materials. Because the exo-olefin-teminated polymer (PIB-Exo) is a commercially available inexpensive product, and used widely for research purposes as well (see e.g., references $48-50$ and references therein), we selected this polymer as one of the starting materials for our studies. As displayed in Figure 1, the commercial PIB-Exo, obtained by utilizing the chain transfer process in conventional carbocationic polymerization of isobutylene, contains not only exo-, but endo- and in-chain olefins as well (see also Figure S1 in the Supporting Information). Considering these double bonds, PIB-Exo has $81 \%$ exo-olefin functionality and $\mathrm{M}_{\mathrm{n}}$ of $1200 \mathrm{~g} / \mathrm{mol}$ by ${ }^{1} \mathrm{H}$ NMR spectroscopy $\left(M_{n}=1150 \mathrm{~g} / \mathrm{mol}\right.$ and $\mathrm{M}_{\mathrm{w}} / \mathrm{M}_{\mathrm{n}}=1.61$ by GPC). The allyl-terminated polyisobutylene (PIB-All) used in this work was obtained by quasiliving carbocationic polymerization of isobutylene and in-situ quenching by ATMS [32]. This polymer has $100 \%$ allyl functionality according to the ${ }^{1} \mathrm{H}$ NMR spectrum of this polymer (Figure 1 and Figure S2), and $M_{n}$ of $820 \mathrm{~g} / \mathrm{mol}$ and $M_{w} / M_{n}$ of 1.16. The reaction routes for obtaining hydroxyl-ended PIBs from these olefin-terminated polymers are depicted in Scheme 1. As expected, hydroboration/oxidation with 9-BBN [31] converts only the exo-olefin in PIB-Exo to hydroxyl groups as indicated in Figure 2 and Figure S4. The endo-olefin and in-chain double bonds do not react due to steric hindrance. The allyl endgroup is fully transformed to hydroxyl group as shown in Figure 3 and Figure S3. The resulting hydroxyl-ended PIBs, that is $\mathrm{PIB}_{\text {exo }}-\mathrm{OH}$ and $\mathrm{PIB}_{\text {all }}-\mathrm{OH}$, react with tosyl chloride $(\mathrm{TsCl})$ and nosyl chloride $(\mathrm{NsCl})$ as displayed in Scheme 1 under various reaction conditions. All reactions were carried out under dry atmosphere at room temperature.

The first attempts on tosylation of $\mathrm{PIB}_{\text {exo }}-\mathrm{OH}$ were carried out to reproduce previously described experiments [47] by applying the same reaction conditions (DCM solvent, 2 eq. of TsCl, 2 eq. of DMAP, 13.7 eq. of TEA, room temperature, $10 \mathrm{~h}$ reaction time). However, surprisingly these conditions did not lead to full conversion of the $\mathrm{PIB}_{\text {exo }}-\mathrm{OH}$. Therefore we tried also pyridine instead of DMAP, different $\mathrm{Ts} C l$ concentrations and various reactions times (Entry 1-3 in Table 1). As shown in Table 1, pyridine alone is not sufficiently effective catalyst of tosylation, leading only to $16 \%$ conversion. As the data indicate in Table 1 and in Figure 2, tenfold excess of $\mathrm{TsCl}$ in the presence of 2 eq. DMAP and 10 eq. TEA leads to complete transformation of the hydroxyl groups in $\mathrm{PIB}_{\text {exo }}-\mathrm{OH}$ to $\mathrm{PIB}$ with tosyl

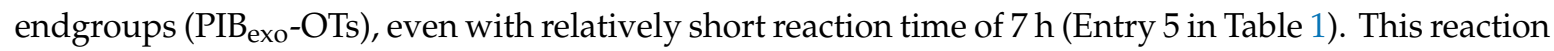
time is sufficient to reach only $80 \%$ conversion during nosylation under the otherwise same condition, bu using THF as solvent, as shown in Table 2 (Entry 11). Because the nosyl chloride has limited solubility in DCM, all nosylation reactions were carried out in THF, which is an appropriate solvent for both $\mathrm{NsCl}$ and $\mathrm{PIB}$. Longer reaction times of nosylation of $\mathrm{PIB}_{\text {exo }}-\mathrm{OH}$ lead to $\sim 90 \%$ conversion, i.e., to the formation of nosyl ended polymers ( $\mathrm{PIB}_{\text {exo }}-\mathrm{ONs}$ ) as indicated by the ${ }^{1} \mathrm{H}$ NMR spectrum in Figure 2. 

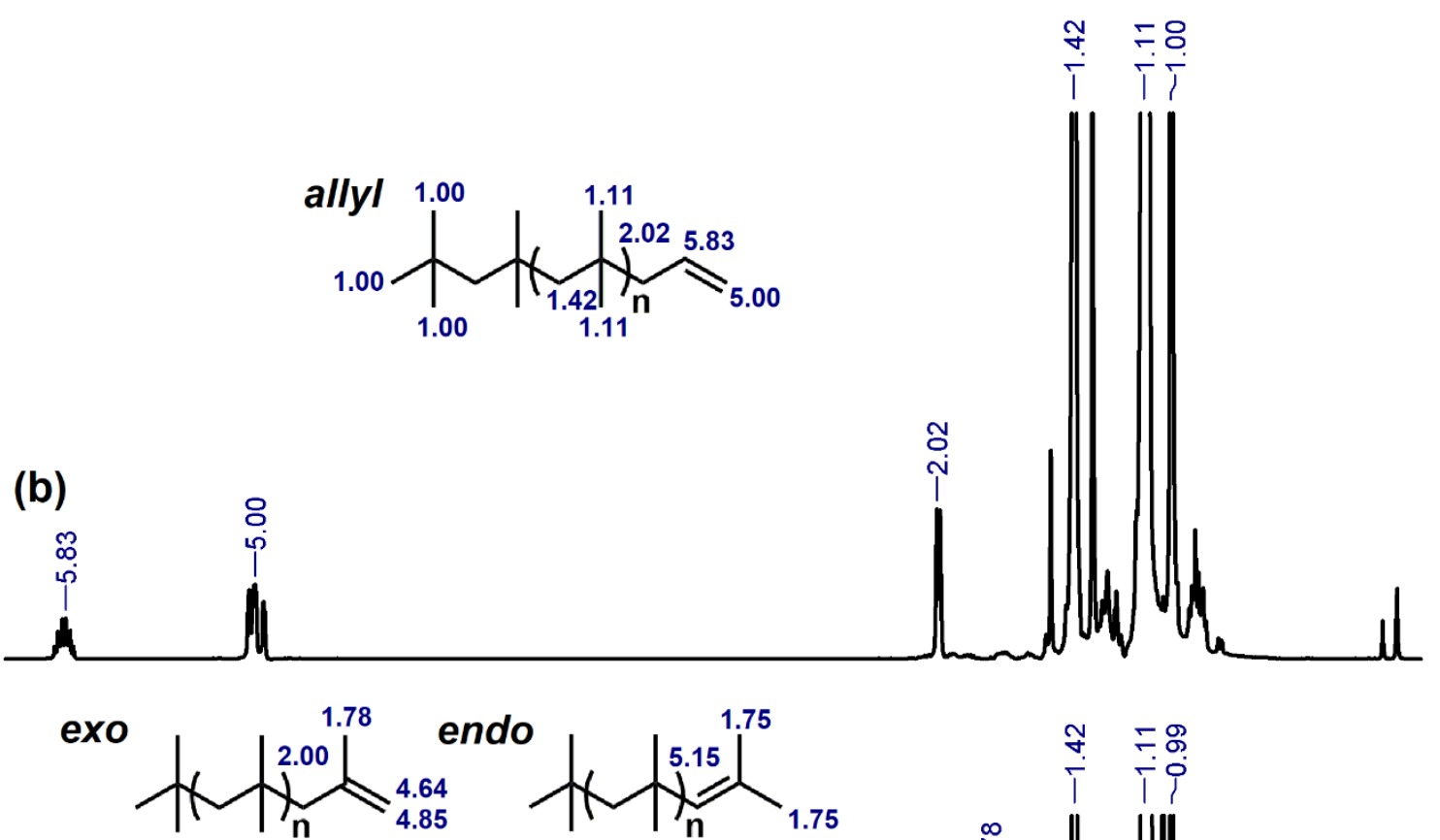

coupled

(a)

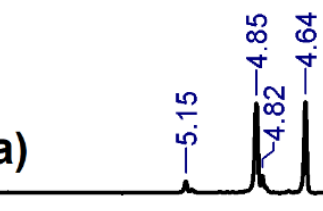

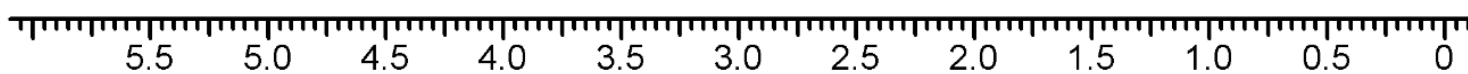
Chemical Shift (ppm)

Figure 1. ${ }^{1} \mathrm{H}$ NMR spectra of the exo-olefin-ended (a) and allyl-terminated polyisobutylene (b).

Table 1. The effect of the reaction conditions on the tosylation of $\mathrm{PIB}_{\text {exo }}-\mathrm{OH}$ at room temperature.

\begin{tabular}{cccccccc}
\hline Entry & Solvent & $\mathbf{t}(\mathbf{h})$ & TsCl (eq.) & Catalyst (eq.) & TEA (eq.) & -OH (\%) & -OTs (\%) \\
\hline $\mathbf{1}$ & DCM & 24 & 1.25 & 4 (pyridine) & 0 & 84 & 16 \\
\hline $\mathbf{2}$ & DCM & 48 & 1.25 & 4 (pyridine) & 0 & 84 & 16 \\
\hline $\mathbf{3}$ & DCM & 72 & 1.25 & 4 (pyridine) & 0 & 84 & 16 \\
\hline $\mathbf{4}$ & DCM & 24 & 5 & 2 (DMAP) & 10 & 25 & 75 \\
\hline $\mathbf{5}$ & DCM & 7 & 10 & 2 (DMAP) & 10 & 0 & 100 \\
\hline $\mathbf{6}$ & DCM & 22 & 10 & 2 (DMAP) & 10 & 0 & 100 \\
\hline $\mathbf{7}$ & DCM & 24 & 10 & 2 (DMAP) & 10 & 0 & 100 \\
\hline $\mathbf{8}$ & DCM & 29 & 10 & 2 (DMAP) & 10 & 0 & 100 \\
\hline $\mathbf{9}$ & DCM & 48 & 10 & 2 (DMAP) & 10 & 0 & 100 \\
\hline $\mathbf{1 0}$ & DCM & 70 & 10 & 2 (DMAP) & 10 & 0 & 100 \\
\hline
\end{tabular}



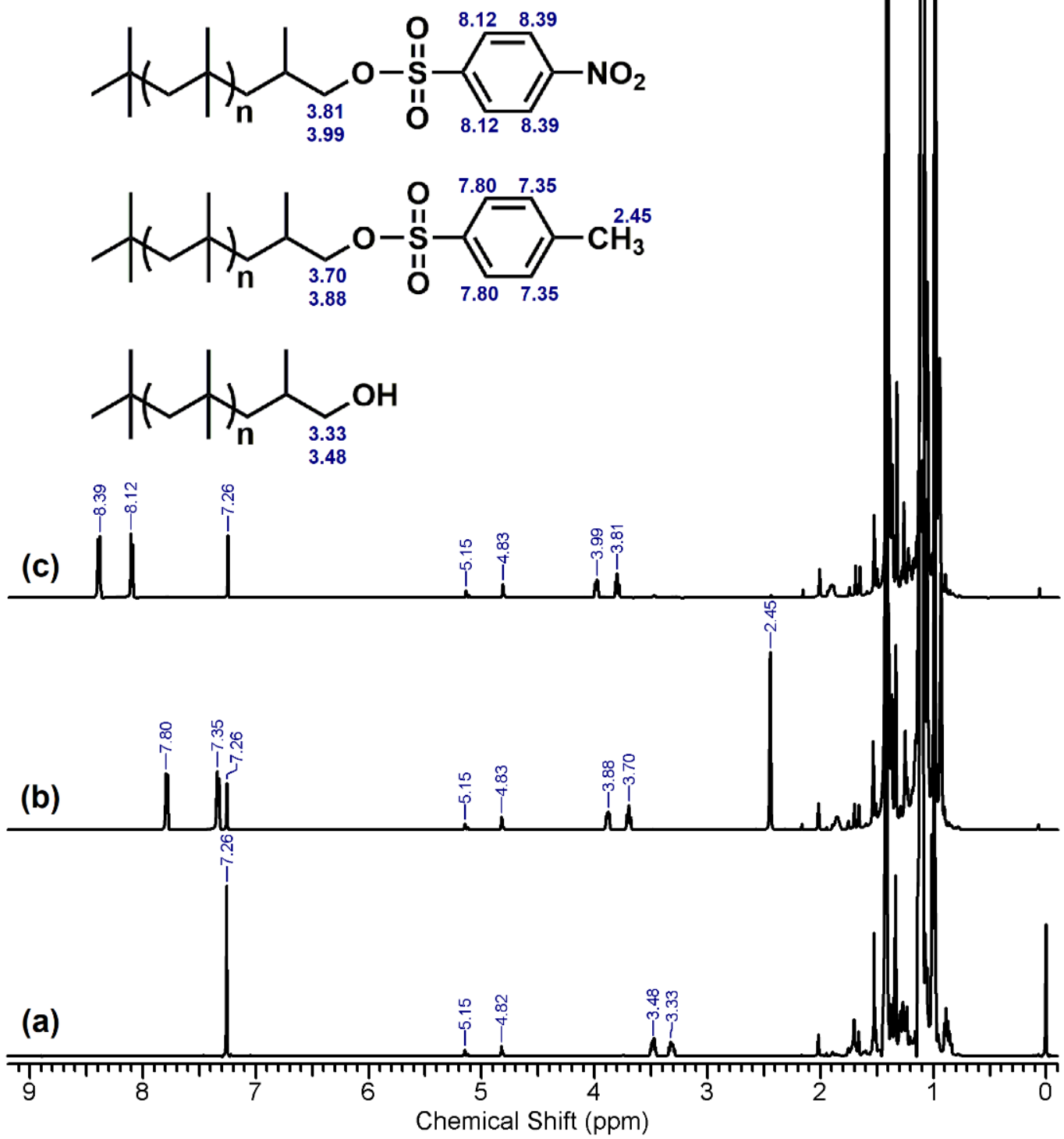

Figure 2. ${ }^{1} \mathrm{H}$ NMR spectra of $\mathrm{PIB}_{\text {exo }}-\mathrm{OH}(\mathbf{a}), \mathrm{PIB}_{\text {exo }}-\mathrm{OTs}(\mathbf{b})$ and $\mathrm{PIB}_{\text {exo }}-\mathrm{ONs}(\mathbf{c})$.

Table 2. The effect of the reaction conditions on the nosylation of $\mathrm{PIB}_{\mathrm{exo}}-\mathrm{OH}$ at room temperature.

\begin{tabular}{cccccccc}
\hline Entry & Solvent & $\mathbf{t}(\mathbf{h})$ & $\mathbf{N s C l}$ (eq.) & Catalyst (eq.) & TEA (eq.) & -OH (\%) & -ONs (\%) \\
\hline $\mathbf{1 1}$ & THF & 7 & 10 & 2 (DMAP) & 10 & 20 & 80 \\
\hline $\mathbf{1 2}$ & THF & 22 & 10 & 2 (DMAP) & 10 & 11 & 89 \\
\hline $\mathbf{1 3}$ & THF & 29 & 10 & 2 (DMAP) & 10 & 12 & 88 \\
\hline $\mathbf{1 4}$ & THF & 70 & 10 & 2 (DMAP) & 10 & 10 & 90 \\
\hline
\end{tabular}


<smiles>CC(CC(C)(C)C)C(C)(C)CCCCl</smiles><smiles>CC(C)(C)CC(C)(C)CCOS(=O)(=O)c1ccc([N+](=O)[O-])cc1</smiles><smiles>Cc1ccc(S(=O)(=O)OCCC(C)(C)CC(C)(C)C)cc1</smiles><smiles>CC(C)(C)CC(C)(C)CC[18OH]</smiles>

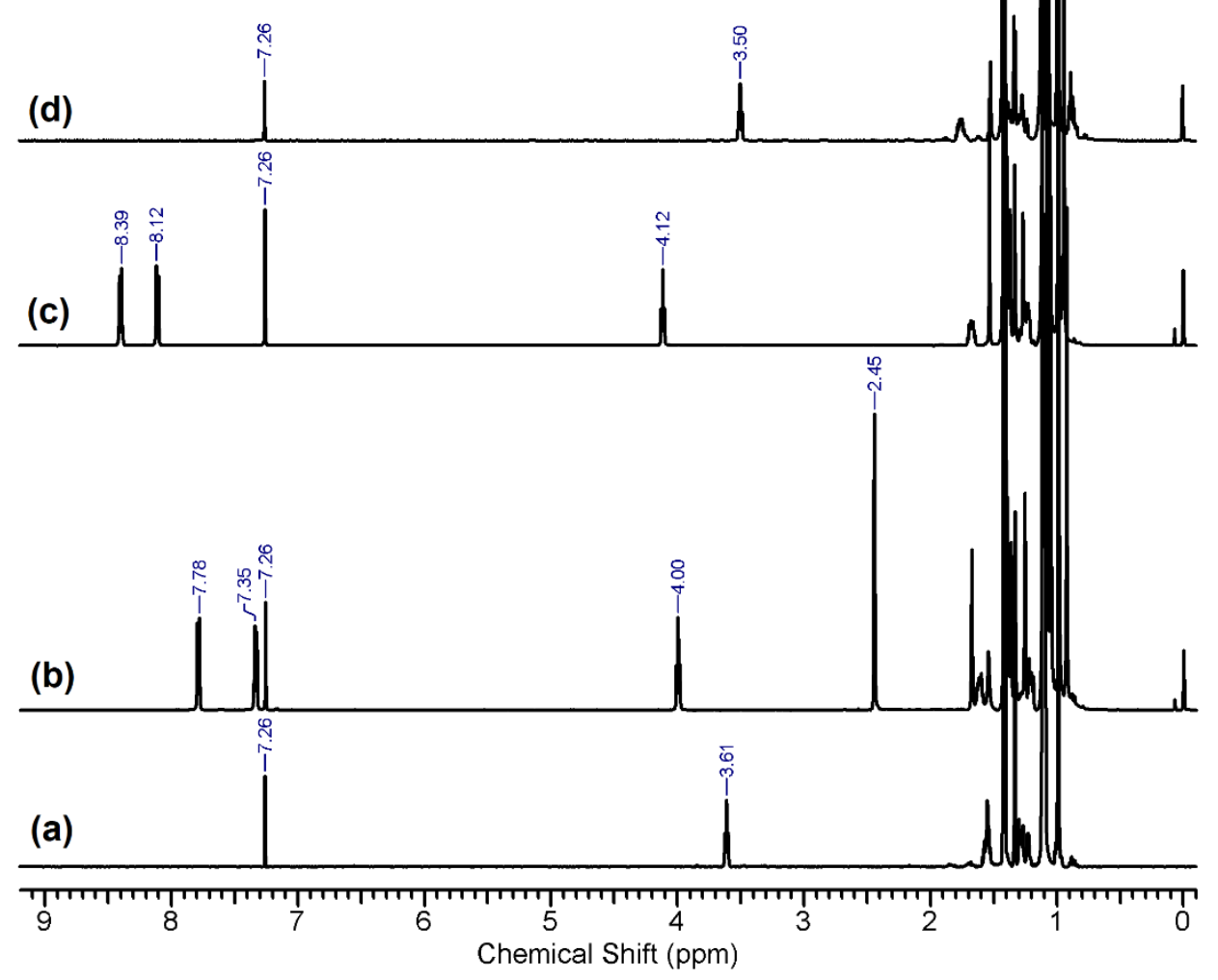

Figure 3. ${ }^{1} \mathrm{H}$ NMR spectra of $\mathrm{PIB}_{\text {all }}-\mathrm{OH}(\mathbf{a}), \mathrm{PIB}_{\text {all }}-\mathrm{OTs}(\mathbf{b}), \mathrm{PIB}_{\text {all }}-\mathrm{ONs}(\mathbf{c})$ and $\mathrm{PIB}_{\mathrm{all}}-\mathrm{Cl}(\mathbf{d})$.

The results of the experiments on the sulfonylation of $\mathrm{PIB}_{\text {exo }}-\mathrm{OH}$ indicated that 10 eq. of the alkyl sulfonyl chloride with the combination of 2 eq. DMAP and 10 eq. TEA results in complete transformation of the hydroxyl group for tosylation and nearly complete conversion for nosylation. Because the PIB-Exo has an extra methyl group connected to the chain terminus compared to the lack of such substituent in the allyl endgroup of PIB-All, it was expected that the latter one has higher reactivity than $\mathrm{PIB}_{\mathrm{exo}}-\mathrm{OH}$. However, using smaller excess of tosyl chloride, that is, only $2-5$ eq., for the tosylation of $\mathrm{PIB}_{\text {all }}-\mathrm{OH}$ resulted in only partial conversion even with longer reaction times as shown in Table 3 (Entry 15-18), on the one hand. On the other hand, alkyl chloride chain end appeared at long reaction times $(72 \mathrm{~h})$. Thus, experiments with tenfold excess of $\mathrm{TsCl}$ reagent were carried out by using the same reaction conditions as for $\mathrm{PIB}_{\text {exo }}-\mathrm{OH}$ with reaction times from $4.5 \mathrm{~h}$ to $72 \mathrm{~h}$ (Entry 19-24 in Table 3). These experiments led to interesting results. First, the transformation of the alcohol chain end is much faster with $\mathrm{PIB}_{a l l}-\mathrm{OH}$, i.e., the reactivity of $\mathrm{PIB}_{a l l}-\mathrm{OH}$ is higher than that of $\mathrm{PIB}_{\text {exo }}-\mathrm{OH}$ with $\mathrm{TsCl}$ as expected. Second, not only tosyl endgroups but PIBs bearing a terminal primary chlorine 
group $\left(\mathrm{PIB}_{\text {all }}-\mathrm{Cl}\right)$ as side products were also observed as indicated by the signal at $3.50 \mathrm{ppm}$ in the ${ }^{1} \mathrm{H}$ NMR spectra which is assigned to the methylene group next to the chlorine termini (Figure 3 ). Furthermore, the amount of $\mathrm{PIB}_{\text {all }}-\mathrm{Cl}$ is increasing, while the amount of tosylated PIB is decreasing with the reaction time as shown in Table 3 (Entry 19-24) and in Figure 4. Therefore, the occurrence of the following processes can be considered to take place according to results with low MW compounds [39] under the applied conditions as depicted in Scheme 2: (1) the initial reaction of the alkyl sulfonyl chloride with the alcohol yields the main tosylated product, (2) meanwhile the $\mathrm{HCl}$ byproduct forms triethylammonium hydrochloride $\left(\mathrm{TEA}^{*} \mathrm{HCl}\right)$ with TEA, in which the chloride ion has a sufficient nucleophilicity to displace the alkyl sulfonyl group. As a consequence, as can be seen in Scheme 2, the first substitution step, i.e., tosylation, is followed by substituting the tosyl group, which is a good leaving group, with chlorine.

Table 3. The effect of the reaction conditions on the tosylation of $\mathrm{PIB}_{\text {all }}-\mathrm{OH}$ at room temperature.

\begin{tabular}{|c|c|c|c|c|c|c|c|c|}
\hline Entry & Solvent & $t(h)$ & $\mathrm{TsCl}$ (eq.) & Catalyst (eq.) & TEA (eq.) & $-\mathrm{OH}(\%)$ & -OTs (\%) & $-\mathrm{Cl}(\%)$ \\
\hline 15 & DCM & 24 & 2 & 2 (DMAP) & 10 & 83 & 17 & 0 \\
\hline 16 & $\mathrm{DCM}$ & 72 & 3 & 2 (DMAP) & 10 & 18 & 61 & 21 \\
\hline 17 & DCM & 24 & 5 & 2 (DMAP) & 10 & 33 & 67 & 0 \\
\hline 18 & DCM & 72 & 5 & 2 (DMAP) & 10 & 51 & 29 & 20 \\
\hline 19 & DCM & 4.5 & 10 & 2 (DMAP) & 10 & 0 & 93 & 7 \\
\hline 20 & DCM & 22 & 10 & 2 (DMAP) & 10 & 0 & 74 & 26 \\
\hline 21 & DCM & 28 & 10 & 2 (DMAP) & 10 & 0 & 69 & 31 \\
\hline 22 & DCM & 46.5 & 10 & 2 (DMAP) & 10 & 0 & 57 & 43 \\
\hline 23 & DCM & 48 & 10 & 2 (DMAP) & 10 & 0 & 56 & 44 \\
\hline 24 & DCM & 72 & 10 & 2 (DMAP) & 10 & 0 & 46 & 54 \\
\hline 25 & DCM & 19 & 10 & 2 (DMAP) & 2 & 47 & 48 & 5 \\
\hline 26 & DCM & 20 & 10 & 2 (DMAP) & 5 & 0 & 89 & 11 \\
\hline 27 & DCM & 50 & 10 & 2 (DMAP) & 5 & 0 & 81 & 19 \\
\hline 28 & DCM & 20 & 10 & 3 (DMAP) & 3 & 0 & 84 & 16 \\
\hline 29 & DCM & 50 & 10 & 3 (DMAP) & 3 & 0 & 79 & 21 \\
\hline 30 & DCM & 19 & 10 & 2 (1-MI) & 2 & 40 & 58 & 2 \\
\hline 31 & DCM & 20 & 10 & 2 (1-MI) & 5 & 0 & 97 & 3 \\
\hline 32 & DCM & 50 & 10 & 2 (1-MI) & 5 & 0 & 94 & 6 \\
\hline 33 & DCM & 20 & 10 & 3 (1-MI) & 3 & 0 & 97 & 3 \\
\hline 34 & DCM & 50 & 10 & 3 (1-MI) & 3 & 0 & 92 & 8 \\
\hline
\end{tabular}

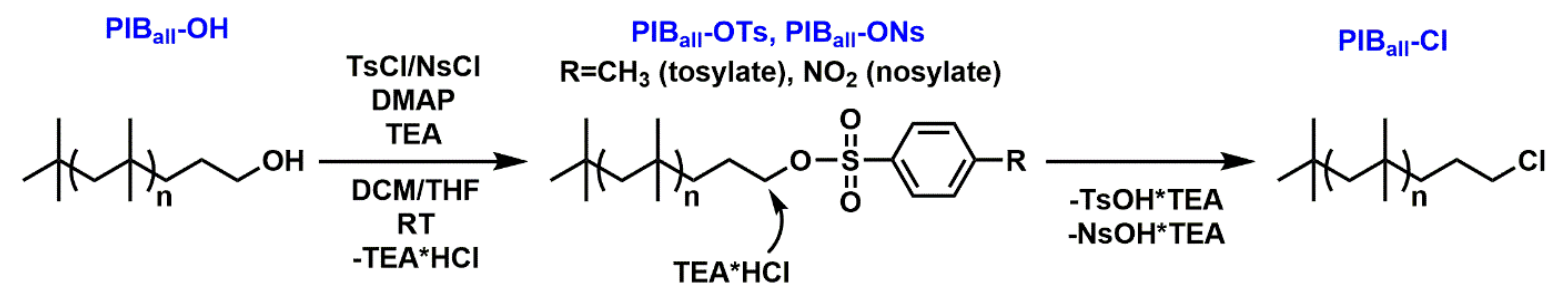

Scheme 2. Tosylation/nosylation of hydroxyl-ended polyisobutylene ( $\left.\mathrm{PIB}_{\text {all }}-\mathrm{OH}\right)$ and subsequent chlorination leading to primary chloride endfunctional polyisobutylene. 


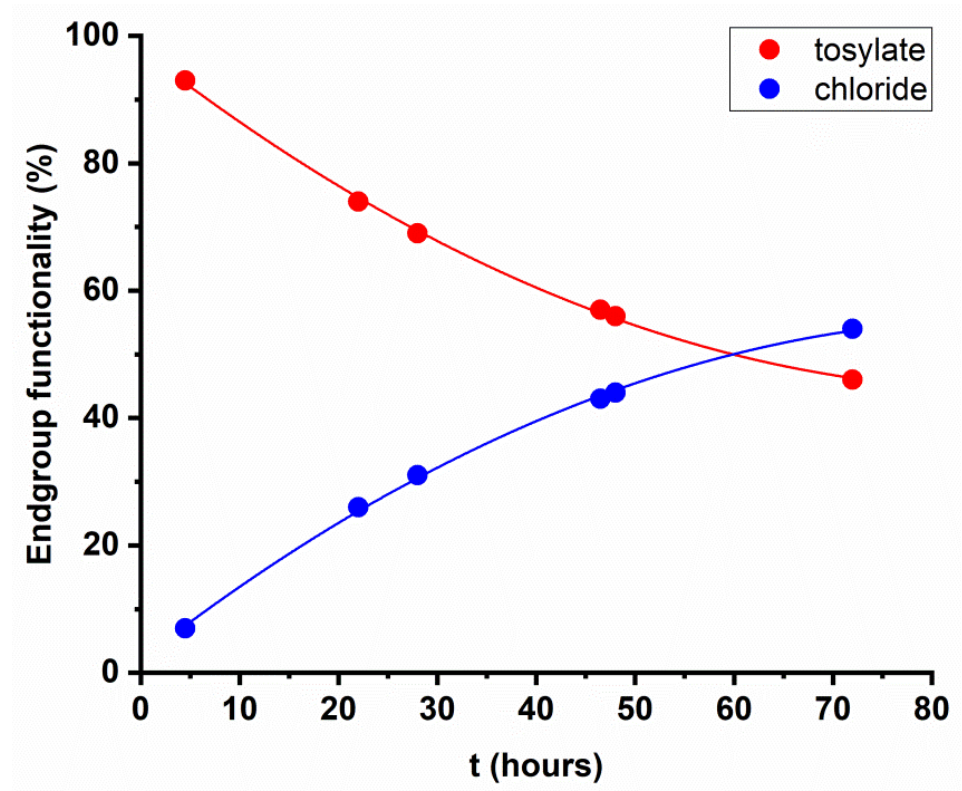

Figure 4. Tosylate and chloride endgroup functionalities as a function of the reaction time of the tosylation of $\mathrm{PIB}_{\text {all }}-\mathrm{OH}$ (Entry 19-24 in Table 3; the lines are drawn only for directing the eye).

Experiments with lower than 10 eq. TEA were also carried out. It was found that although 2 eq. TEA results in 5\% chloride endgroup (Entry 25), which is much smaller than that obtained with 10 eq. (Entry 20 in Table 3) at similar reaction time. However, only 53\% of the hydroxyl group is consumed in this reaction (Entry 25 in Table 3). Increasing the amount of TEA to 3 eq. and 5 eq. leads to complete conversion of the hydroxyl groups and nearly $90 \%$ tosylate functionality is observed with 5 eq. of TEA in $20 \mathrm{~h}$ reaction time. Summarizing the results of tosylation of $\mathrm{PIB}_{\text {all }}-\mathrm{OH}$ with TsCl obtained with DMAP catalyst in the presence of TEA in the range of 5-10 eq. it can be claimed that with 10 eq. TsCl PIB-tosylates with around 90\% tosyl functionalities and $10 \%$ of $\mathrm{PIB}_{\text {all }}-\mathrm{Cl}_{\text {can }}$ be prepared. As reported in the literature [40], not only DMAP but 1-methylimidazole (1-MI) is also an efficient catalyst of acylation of alcohols. Therefore, attempts were made by us to investigate the effect of 1-MI on the tosylation reaction of $\mathrm{PIB}_{\text {all }}-\mathrm{OH}$ by still keeping the amount of TEA at relatively low levels as shown in Table 3. As indicated by the results of Entry 30-34, 2 eq. TEA is insufficient to reach high tosylation yields, but with 3 eq. and 5 eq. of TEA, the consumption of the hydroxyl groups is complete, the undesired side reaction of chlorination is suppressed to $3-8 \%$, and thus PIB $_{\text {all }}$-tosylates with $92-97 \%$ tosylate endfunctionalities are obtained as confirmed by the ${ }^{1} \mathrm{H}$ NMR spectrum in Figure 3. These optimal reaction conditions by using 1-MI as catalyst of tosylation of $\mathrm{PIB}_{\text {all }}-\mathrm{OH}$ provide an efficient tool to prepare tosylate-ended PIBs with high, nearly quantitative endfunctionalities. Due to the fact that the PIB-All prepolymer with narrow MWD is synthesized by quasiliving carbocationic polymerization of isobutylene, well-defined $\mathrm{PIB}_{\text {all }}$-OTs also with narrow MWD can be obtained by this process. Thus, the resulting $\mathrm{PIB}_{\text {all }}$-OTs can be utilized in various further derivatization reactions and as a starting material for macromolecular assemblies of complex architectures.

The effect of the reaction conditions on the nosylation of $\mathrm{PIB}_{\text {all }}-\mathrm{OH}$ was also investigated. As shown in Table 4, the consumption of the terminal hydroxyl groups is complete in the presence of 10 eq. $\mathrm{NsCl}, 2$ eq. DMAP and 10 eq. TEA after $4 \mathrm{~h}$ reaction time (Entry 35-39). However, with this and longer reaction times from $14 \%$ to $30 \%$ chlorine endgroups are also present in the resulting polymers. Decreasing the amount of TEA to 2 eq. gives only $14 \%$ nosylation conversion in $19 \mathrm{~h}$. Using reduced amounts of TEA of 3 eq. and 5 eq. results in complete hydroxyl consumption, and in the case of 5 eq. TEA 91\% and 93\% nosyl endfunctionalities are observed (Entry 45 and 46 in Table 4). With 1-MI as catalyst, $\mathrm{PIB}_{\text {all }}-\mathrm{ONs}$ with $89-94 \%$ nosyl endfunctionalities are formed as the ${ }^{1} \mathrm{H}$ NMR spectra and the data in Table 4 indicate (Figure 3). In these cases, negligible amounts of $2-5 \% \mathrm{PIB}_{\text {all }}$-ONs with unreacted hydroxyl termini can also be observed, and the chlorine endfunctionalities fall in the region 
of $4-8 \%$. These results show that $\mathrm{PIB}_{\text {all }}-\mathrm{ONs}$ with higher than $90 \%$ nosyl functionalities can be obtained with either DMAP or 1-MI catalyst by using 5 eq. of TEA and proper reaction times. Based on the reactivity of the nosyl group, these novel nosyl-ended PIBs, unpublished so far in the open literature according to the best of our knowledge, are expected to open new ways for the preparation of various PIB-based polymer architectures.

Table 4. The effect of the reaction conditions on the nosylation of $\mathrm{PIB}_{\mathrm{all}}-\mathrm{OH}$ at room temperature.

\begin{tabular}{ccccccccc}
\hline $\mathbf{9}$ & Solvent & $\mathbf{t}(\mathbf{h})$ & $\mathbf{N s C l}$ (eq.) & Catalyst (eq.) & TEA (eq.) & -OH (\%) & -ONs (\%) & -Cl (\%) \\
\hline 35 & THF & 1 & 10 & 2 (DMAP) & 10 & 8 & 89 & 3 \\
\hline 36 & THF & 2 & 10 & 2 (DMAP) & 10 & 3 & 93 & 4 \\
\hline 37 & THF & 3 & 10 & 2 (DMAP) & 10 & 2 & 94 & 4 \\
\hline 38 & THF & 4 & 10 & 2 (DMAP) & 10 & 2 & 92 & 6 \\
\hline 39 & THF & 4.5 & 10 & 2 (DMAP) & 10 & 0 & 86 & 14 \\
\hline 40 & THF & 22 & 10 & 2 (DMAP) & 10 & 0 & 82 & 18 \\
\hline 41 & THF & 28 & 10 & 2 (DMAP) & 10 & 0 & 82 & 18 \\
\hline 42 & THF & 46.5 & 10 & 2 (DMAP) & 10 & 0 & 81 & 19 \\
\hline 43 & THF & 72 & 10 & 2 (DMAP) & 10 & 0 & 71 & 29 \\
\hline 44 & THF & 19 & 10 & 2 (DMAP) & 2 & 86 & 9 & 5 \\
\hline 45 & THF & 20 & 10 & 2 (DMAP) & 5 & 1 & 92 & 7 \\
\hline 46 & THF & 50 & 10 & 2 (DMAP) & 5 & 0 & 91 & 9 \\
\hline 47 & THF & 20 & 10 & 3 (DMAP) & 3 & 0 & 81 & 19 \\
\hline 48 & THF & 50 & 10 & 3 (DMAP) & 3 & 0 & 72 & 28 \\
\hline 49 & THF & 19 & 10 & 2 (1-MI) & 2 & 49 & 38 & 13 \\
\hline 50 & THF & 20 & 10 & 2 (1-MI) & 5 & 2 & 94 & 4 \\
\hline 51 & THF & 50 & 10 & 2 (1-MI) & 5 & 2 & 90 & 8 \\
\hline 52 & THF & 20 & 10 & 3 (1-MI) & 3 & 5 & 91 & 4 \\
\hline 53 & THF & 50 & 10 & 3 (1-MI) & 3 & 5 & 89 & 6 \\
\hline
\end{tabular}

\section{Conclusions}

Tosylation and nosylation of hydroxyl-ended polyisobutylenes (PIB-OHs) derived from a commercially available exo-olefin-terminated polymer $\left(\mathrm{PIB}_{\text {exo }}-\mathrm{OH}\right)$ and from allyl-ended macromolecules ( $\mathrm{PIB}_{\text {all }}-\mathrm{OH}$ ), prepared by quasiliving carbocationic polymerization of isobutylene, were systematically investigated. A thorough exploration was conducted to reveal the influence of the ratios of the reagents, such as 4-dimethylaminopyridine (DMAP), pyridine, 1-methylimidazole (1-MI), and trimethylamine (TEA), and reaction time on the conversion of the hydroxyl termini in these PIB-OHs. A significant difference in the reactivity between the two hydroxyl-terminated polymers was found, i.e., the $\mathrm{PIB}_{\text {all }}-\mathrm{OH}$ reacts faster with the sulfonyl chlorides than the $\mathrm{PIB}_{\text {exo }}-\mathrm{OH}$, presumably because of steric reasons. While quantitative tosylation was achieved with $\mathrm{PIB}_{\text {exo }}-\mathrm{OH}$, nosylation

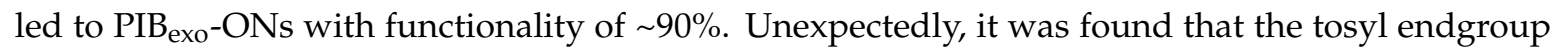
reacts further with the chloride ion formed during tosylation, and chlorine-ended PIB ( $\mathrm{PIB}$ all-Cl) is formed. The conversion of the hydroxyl group and the relative amount of the sulfonyl and chlorine termini strongly depend on TEA and reaction times. Decreased amounts of TEA in the range of 3-5 eq. and optimal reaction times lead to $\mathrm{PIB}_{\text {all }}-\mathrm{OTs}$ and $\mathrm{PIB}_{\text {all }}$-ONs with higher than $90 \%$ sulfonyl functionalities. The resulting tosyl- and nosyl-ended PIBs are capable of subsequent derivatizations, and thus various novel endfunctional PIBs can be obtained via substitution reactions. This enables the preparation of an array of PIB-containing new macromolecular architectures not existed before. 
Supplementary Materials: The following are available online at http://www.mdpi.com/2073-4360/12/11/2504/s1, Figure S1: 1H NMR spectrum of the PIB-Exo sample with integral values; Figure S2: 1H NMR spectrum of the PIB-All sample with integral values; Figure S3: 1H NMR spectrum of the PIBall-OH sample with integral values; Figure S4: 1H NMR spectrum of the PIBexo-OH sample with integral values; Figure S5: 1H NMR spectrum of the PIBall-OTs sample with integral values; Figure S6: 1H NMR spectrum of the PIBall-ONs sample with integral values; Figure S7: GPC curves of the synthesized PIBall-OTs macroinitiator and its starting material PIBall-OH; Figure S8: GPC curves of the synthesized PIBall-ONs macroinitiator and its starting material PIBall-OH.

Author Contributions: All authors designed and contributed to this study. Conceptualization, B.P., T.M.T., Á.S., G.S., B.K., R.M., B.I.; Methodology, B.P., T.M.T., Á.S., G.S., B.K., B.I.; Analysis, B.P., T.M.T., Á.S., G.S., B.K.; Data evaluation, B.P., T.M.T., Á.S., G.S., B.K., R.M., B.I.; Writing—Draft Preparation, B.P., T.M.T., Á.S., G.S., B.K., B.I.; Writing-Review \& Editing, B.P., T.M.T., Á.S., G.S., B.K., R.M., B.I.; Supervision, R.M., B.I.; Funding Acquisition, R.M., B.I.; All authors have read and agreed to the published version of the manuscript.

Funding: This research was funded by the National Research, Development and Innovation Office (NRDIO), Hungary (NN116252, NN129366, K135946), and the German Research Foundation (DFG; MU 836/13-1, 269965048) in the framework of the European Research Area Chemistry (ERA-Chemistry) and the NRDIO's international cooperation programs.

Acknowledgments: The authors gratefully acknowledge the support by the European Research Area Chemistry (ERA-Chemistry) program, the National Research, Development and Innovation Office, Hungary (NN116252, NN129366, K135946) and the German Research Foundation (DFG; MU 836/13-1, 269965048).

Conflicts of Interest: The authors declare no conflict of interest.

\section{References}

1. Rajasekhar, T.; Singh, G.; Kapur, G.S.; Ramakumar, S.S.V. Recent advances in catalytic chain transfer polymerization of isobutytene: A review. RSC Adv. 2020, 10, 18180-18191. [CrossRef]

2. Kulai, I.; Karpus, A.; Bergbreiter, D.E.; Al-Hashimi, M.; Bazzi, H.S. Organocatalytic Michael Addition as a Method for Polyisobutylene Chain-End Functionalization. Macromol. Rapid Commun. 2020, 41, 2000382. [CrossRef]

3. Parada, C.M.; Yang, B.; Campbell, C.G.; Storey, R.F. Synthesis, characterization, and photopolymerization of (meth)acrylate-functional polyisobutylene macromers produced by cleavage/alkylation of butyl rubber. J. Polym. Sci. 2020, 58, 2807-2822. [CrossRef]

4. Berezianko, I.A.; Vasilenko, I.V.; Kostjuk, S.V. Cationic polymerization of isobutylene co-initiated by chloroferrate imidazole-based ionic liquid: The advantageous effect of initiator and aromatic compounds. Eur. Polym. J. 2019, 121, 109307. [CrossRef]

5. Shiman, D.I.; Vasilenko, I.V.; Kostjuk, S.V. Alkoxy aluminum chlorides in the cationic polymerization of isobutylene: A co-initiator, carbocation stabilizer and chain-transfer agent. Polym. Chem. 2019, 10, 5998-6002. [CrossRef]

6. Li, X.; Wu, Y.; Zhang, J.; Li, S.; Zhang, M.; Yang, D.; Wang, H.; Shang, Y.; Guo, W.; Yan, P. Synthesis of Highly Reactive Polyisobutylenes via Cationic Polymerization in Ionic Liquids: Characteristics and Mechanism. Polym. Chem. 2019, 10, 201-208. [CrossRef]

7. Campbell, C.G.; Storey, R.F. Functional Polyisobutylenes via Electrophilic Cleavage/Alkylation. J. Polym. Sci. Part A Polym. Chem. 2017, 55, 1991-1997. [CrossRef]

8. Yang, X.J.; Guo, A.R.; Xu, H.C.; Wu, Y.X. Direct synthesis of highly reactive polyisobutylenes via cationic polymerization of isobutylene co-initiated with TiCl4 in nonpolar hydrocarbon media. J. Appl. Polym. Sci. 2015, 132, 42232. [CrossRef]

9. Guo, A.R.; Yang, X.J.; Yan, P.F.; Wu, Y.X. Synthesis of highly reactive polyisobutylenes with exo-olefin terminals via controlled cationic polymerization with $\mathrm{H}_{2} \mathrm{O} / \mathrm{FeCl}_{3} / \mathrm{iPrOH}$ initiating system in nonpolar hydrocarbon media. J. Polym. Sci. Part A Polym. Chem. 2013, 51, 4200-4212. [CrossRef]

10. Chang, T.X.; Wei, Z.T.; Wu, M.Y.; Zhang, H.T.; Gao, Y.Z.; Wu, Y.X. Amphiphilic Chitosan-g-Polyisobutylene Graft Copolymers: Synthesis, Characterization, and Properties. ACS Appl. Polym. Mater. 2020, 2, $234-247$. [CrossRef]

11. Wu, K.D.; Wu, Y.B.; Huang, S.; Chen, Z.F.; Wang, H.; Shang, Y.W.; Li, S.X. Synthesis and characterization of hydroxyl-terminated butadiene-end-capped polyisobutylene and its use as a diol for polyurethane preparation. RSC Adv. 2020, 10, 9601-9609. [CrossRef]

12. Yang, B.; Storey, R.F. Synthesis and characterization of polyisobutylene telechelic prepolymers with epoxide functionality. React. Funct. Polym. 2020, 150, 104563. [CrossRef] 
13. Holbrook, T.P.; Storey, R.F. Micellization and Adsorption to Carbon Black of Polyisobutylene-Based Ionic Liquids. J. Polym. Sci. 2020, 58, 280-299. [CrossRef]

14. Nugay, T.; Nugay, N.; Kennedy, J.P. Synthesis, characterization and end-functionalization of a novel telechelic star: Styrene hexamer core carrying polyisobutylene arms fitted with allyl termini. Polym. Bull. 2019. [CrossRef]

15. Li, J.; Wu, K.D.; Shan, H.; Zhang, J.H.; Zhao, M.; Gong, G.B.; Guo, W.L.; Wu, Y.B. Synthesis and Properties of Hydroxytelechelic Polyisobutylenes by End Capping with tert-Butyl-dimethyl-(4-methyl-pent-4enyloxy)-silane. Chin. J. Polym. Sci. 2019, 37, 936-942. [CrossRef]

16. Gao, Y.Z.; Chang, T.X.; Wu, Y.X. In-situ synthesis of acylated sodium alginate-g-(tetrahydrofuran(5)-bpolyisobutylene) terpolymer/Ag-NPs nanocomposites. Carbohydr. Polym. 2019, 219, 201-209. [CrossRef]

17. Parada, C.M.; Parker, G.L.; Storey, R.F. Polyisobutylene Containing Covalently Bound Antioxidant Moieties. J. Polym. Sci. Part A Polym. Chem. 2019, 57, 1836-1846. [CrossRef]

18. Kurnaz, E.; Helvacioglu, E.; Kekec, N.C.; Nugay, N.; Nugay, T.; Kennedy, J.P. High-Molecular-Weight Polyisobutylenes (PIBs) and PIB Networks from Liquid PIBs by Thiol-Ene Clicking. J. Polym. Sci. Part A Polym. Chem. 2019, 57, 1197-1208. [CrossRef]

19. Yang, B.; Storey, R.F. Chain-End Functionalization of Living Polyisobutylene via an End-Quenching Comonomer That Terminates by Indanyl Ring Formation. Macromolecules 2018, 51, 6552-6560. [CrossRef]

20. Wu, Y.B.; Li, K.; Xiang, D.; Zhang, M.; Yang, D.; Zhang, J.H.; Mao, J.; Wang, H.; Guo, W.L. Surface immobilization of heparin on functional polyisobutylene-based thermoplastic elastomer as a potential artificial vascular graft. Appl. Surf. Sci. 2018, 445, 8-15. [CrossRef]

21. Deodhar, T.J.; Keszler, B.L.; Kennedy, J.P. Quantitative Preparation of Allyl Telechelic Polyisobutylene under Reflux Conditions. J. Polym. Sci. Part A Polym. Chem. 2017, 55, 1784-1789. [CrossRef]

22. Yang, B.; Storey, R.F. End-quenching of tert-chloride-terminated polyisobutylene with alkoxybenzenes: Comparison of $\mathrm{AlCl} 3$ and TiCl4 catalysts. Polym. Chem. 2015, 6, 3764-3774. [CrossRef]

23. Appiah, C.; Akbarzadeh, J.; Stojanovic-Marinow, A.; Peterlik, H.; Binder, W.H. Hierarchically Mesostructured Polyisobutylene-Based Ionic Liquids. Macromol. Rapid Commun. 2016, 37, 1175-1180. [CrossRef] [PubMed]

24. Kostjuk, S.V.; Yeong, H.Y.; Voit, B. Cationic Polymerization of Isobutylene at Room Temperature. J. Polym. Sci. Part A Polym. Chem. 2013, 51, 471-486. [CrossRef]

25. Kostjuk, S.V. Recent Progress in the Lewis Acid Co-Initiated Cationic Polymerization of Isobutylene and 1,3-Dienes. RSC Adv. 2015, 5, 13125-13144. [CrossRef]

26. Kumar, R.; Zheng, B.; Huang, K.-W.; Emert, J.; Faust, R. Synthesis of Highly Reactive Polyisobutylene Catalyzed by EtAlCl 2 /Bis(2-Chloroethyl) Ether Soluble Complex in Hexanes. Macromolecules 2014, 47, 1959-1965. [CrossRef]

27. Rajasekhar, T.; Haldar, U.; Emert, J.; Dimitrov, P.; Severt, R.; Faust, R. Catalytic Chain Transfer Polymerization of Isobutylene: The Role of Nucleophilic Impurities. J. Polym. Sci. Part A Polym. Chem. 2017, 55, 3697-3704. [CrossRef]

28. Vasilenko, I.V.; Nikishev, P.A.; Shiman, D.I.; Kostjuk, S.V. Cationic Polymerization of Isobutylene in Toluene: Toward Well-Defined Exo-Olefin Terminated Medium Molecular Weight Polyisobutylenes under Mild Conditions. Polym. Chem. 2017, 8, 1417-1425. [CrossRef]

29. Rajasekhar, T.; Emert, J.; Faust, R. Synthesis of Highly Reactive Polyisobutylene by Catalytic Chain Transfer in Hexanes at Elevated Temperatures; Determination of the Kinetic Parameters. Polym. Chem. 2017, 8, 2852-2859. [CrossRef]

30. Jin, Y.; Dong, K.; Xu, L.; Guo, X.; Cheng, R.; Liu, B. Facile Synthesis of Medium Molecular Weight Polyisobutylene with Remarkable Efficiency Employing the Complexed BF3·EtOH/TiCl4·H2O Initiating System. Eur. Polym. J. 2019, 120, 109204. [CrossRef]

31. Iván, B.; Kennedy, J.P.; Chang, V.S.C. New telechelic polymers and sequential copolymers by polyfunctional initiator-transfer agents (inifers). VII. Synthesis and characterization of $\alpha, \omega$-di (hydroxy)polyisobutylene. J. Polym. Sci. Part A Polym. Chem. 1980, 18, 3177-3191. [CrossRef]

32. Iván, B.; Kennedy, J.P. Living Carbocationic Polymerization. XXX. One-Pot Synthesis of Allyl-Terminated Linear and Tri-Arm Star Polyisobutylenes, and Epoxy- and Hydroxy-Telechelics Therefrom. J. Polym. Sci. Part A Polym. Chem. 1990, 28, 89-104. [CrossRef]

33. Kennedy, J.P.; Chang, V.S.; Smith, R.A.; Iván, B. New telechelic polymers and sequential copolymers by polyfunctional initiator-transfer agents (inifers) V. synthesis of $\alpha$-tert-butyl- $\omega$-isopropenylpolyisobutylene and $\alpha, \omega$-di(isopropenyl) polyisobutylene. Polym. Bull. 1979, 1, 575-580. [CrossRef] 
34. Nielsen, L.V.; Nielsen, R.R.; Gao, B.; Kops, J.; Iván, B. Synthesis of isobutenyl-telechelic polyisobutylene by functionalization with isobutenyltrimethylsilane. Polymer 1997, 38, 2529-2534. [CrossRef]

35. Simison, K.L.; Stokes, C.D.; Harrison, J.J.; Storey, R.F. End-quenching of quasiliving carbocationic isobutylene polymerization with hindered bases: Quantitative formation of exo-olefin-terminated polyisobutylene. Macromolecules 2006, 39, 2481-2487. [CrossRef]

36. Kennedy, J.P.; Iván, B. Designed Polymers by Carbocationic Macromolecular Engineering: Theory and Practice; Hanser Publishers: Munich, NY, USA, 1992; ISBN 0-19-52092 1-4.

37. Höfle, G.; Steglich, W.; Vorbrüggen, H. 4-Dialkylaminopyridines as Highly Active Acylation Catalysts. Angew. Chem. Int. Ed. 1978, 17, 569-583. [CrossRef]

38. Yoshida, Y.; Sakakura, Y.; Aso, N.; Okada, S.; Tanabe, Y. Practical and Efficient Methods for Sulfonylation of Alcohols Using Ts(Ms)Cl/Et3N and Catalytic Me3H·HCl as Combined Base: Promising Alternative to Traditional Pyridine. Tetrahedron 1999, 55, 2183-2192. [CrossRef]

39. Ding, R.; He, Y.; Wang, X.; Xu, J.; Chen, Y.; Feng, M.; Qi, C. Treatment of Alcohols with Tosyl Chloride Does Not Always Lead to the Formation of Tosylates. Molecules 2011, 16, 5665-5673. [CrossRef]

40. Wu, Q.P.; Liu, H.; Liu, H.X.; Chen, X.; Wang, H.; Zhang, Q.S.; Li, Y.Z. Practical and Efficient Acylation and Tosylation of Sterically Hindered Alcohols Catalyzed with 1-Methylimidazole. Chem. Res. Chin. Univ. 2010, $26,55-59$.

41. Asano, K.; Matsubara, S. Amphiphilic Organocatalyst for Schotten-Baumann-Type Tosylation of Alcohols under Organic Solvent Free Condition. Org. Lett. 2009, 11, 1757-1759. [CrossRef]

42. Hwang, C.K.; Li, W.S.; Nicolaou, K.C. Reactions of Hydroxyl Groups with Tosylchloride-Dimethylaminopyridine System. Direct Synthesis of Chlorides from Hydroxycompounds. Tetrahedron Lett. 1984, 25, 2295-2296. [CrossRef]

43. Kolb, H.C.; VanNieuwenhze, M.S.; Sharpless, K.B. Catalytic Asymmetric Dihydroxylation. Chem. Rev. 1994, 94, 2483-2547. [CrossRef]

44. Pasto, D.J.; Cottard, F.; Jumelle, L. Photooxidation of Alkyl4-Nitrophenyl Sulfides and Sulfoxides. Observation of Oxidative C-S Bond Cleavage and Rearrangement Reactions. J. Am. Chem. Soc. 1994, 116, 8978-8984. [CrossRef]

45. De Castro, K.; Rhee, H. Selective Nosylation of 1-Phenylpropane-1,3-Diol and Perchloric Acid Mediated Friedel-Crafts Alkylation: Key Steps for the New and Straightforward Synthesis of Tolterodine. Synthesis 2008, 12, 1841-1844. [CrossRef]

46. Glassner, M.; D’hooge, D.R.; Young Park, J.; Van Steenberge PH, M.; Monnery, B.D.; Reyniers, M.-F.; Hoogenboom, R. Systematic Investigation of Alkyl Sulfonate Initiators for the Cationic Ring-Opening Polymerization of 2-Oxazolines Revealing Optimal Combinations of Monomers and Initiators. Eur. Polym. J. 2015, 65, 298-304. [CrossRef]

47. Percec, V.; Guhaniyogi, S.C.; Kennedy, J.P.; Ivan, B. New Telechelic Polymers and Sequential Copolymers by Polyfunctional Initiator-Transfer Agents (Inifers) 22. Syntehsis and Characterization of Linear and Three-Arm Star Block Copolymers of Isobutylene and N-Acetylethyleneimine. Polym. Bull. 1982, 8, 25-32. [CrossRef]

48. Kerscher, B.; Trötschler, T.M.; Pásztói, B.; Gröer, S.; Szabó, Á.; Iván, B.; Mülhaupt, R. Thermoresponsive Polymer Ionic Liquids and Nanostructured Hydrogels Based upon Amphiphilic Polyisobutylene-b-Poly(2-Ethyl-2-Oxazoline) Diblock Copolymers. Macromolecules 2019, 52, 3306-3318. [CrossRef]

49. Li, J.; Sung, S.; Tian, J.; Bergbreiter, D.E. Polyisobutylene Supports a Non-Polar Hydrocarbon Analog of PEG Supports. Tetrahedron 2005, 61, 12081-12092. [CrossRef]

50. Bergbreiter, D.E.; Li, J. Terminally Functionalized Polyisobutylene Oligomers as Soluble Supports in CatalysisElectronic Supplementary Information (ESI) Available: Experimental Details for the Synthesis and Use of the PIB Oligomers and Catalysts. Chem. Commun. 2004, 10, 42. [CrossRef]

Publisher's Note: MDPI stays neutral with regard to jurisdictional claims in published maps and institutional affiliations. 